\title{
Evaluation of cerebroprotective effect of Ricinus communis leaves against ischemia reperfusion injury in rats
}

\author{
Nesar Ahmad, Anuradha Mishra* (D), Farogh Ahsan and Zafar Khan
}

\begin{abstract}
Background: Ricinus communis (RC) has been used for a long time as natural origin medicine in the treatment of central nervous system ailments. This present study was designed to identify the possible role of Ricinus communis leaves extract against ischemia-reperfusion induced-neurobehavioral changes, oxidative stress, histopathological and cellular modifications in the brain.

Methods: Sprague Dawley (SD) rats (200-250 g) were induced to bilateral common carotid artery occlusion (BCCAO) for around $30 \mathrm{~min}$ later subjected to reperfusion for $24 \mathrm{~h}$ to induce cerebral injury by reperfusion. Ricinus communis leaves extract ( 250 and $500 \mathrm{mg} / \mathrm{kg}$, p.o) was administered continuously for 14 days and on the 15th-day animals were subjected to ischemia-reperfusion injury. Different behavioral tests and biochemical parameters were assessed subsequently.

Results: Fourteen days Ricinus communis leaves extract (250 and $500 \mathrm{mg} / \mathrm{kg}$, p.o.) treatment very significantly improved neurobehavioral alterations when compared to control ischemia-reperfusion. Ricinus communis leaves extract (250 and $500 \mathrm{mg} / \mathrm{kg}$, p.o.) kg, i.p. treatment significantly attenuated oxidative damage when compared to ischemia-reperfusion (I/R) group animals. In addition, Ricinus communis leaves extract treatment was well supported histopathologically when compared to the ischemia-reperfusion (I/R) group.

Conclusion: The data from this study recommend that treatment with Ricinus communis leaves extract increases the antioxidant protection against BCCAO-induced global cerebral ischemia and demonstrates neuroprotective activity.
\end{abstract}

Keywords: Ricinus communis, Ischemia, Reperfusion, Neuroprotective, Cerebral ischemia

\section{Introduction}

Cerebrovascular diseases are among the second leading cause of death and therefore the main explanation for adult long-run incapability in developed countries. The world health Organization places the worldwide incidence of stroke at around two hundred cases per one hundred thousand inhabitants, though this data vary among countries [1]. Cerebral ischemia or brain anemia may be a condition that happens once there is no enough blood flow to the brain to fulfill metabolic

\footnotetext{
* Correspondence: misra.anuradha@gmail.com

Faculty of Pharmacy, Integral University, Lucknow, UP, India
}

demand and it results from occlusion of a serious arteria cerebri by a clot or an embolism, that ends up in the reduction of blood flow in the cerebrum, a condition of oxygen and aldohexose deprivation (AHD), and later harm the tissue within the affected region [2].

The brain is especially at risk of damage because of aerophilous stress due to constituents of neurons which are made up of unsaturated fatty acids and levels of endogenous inhibitor enzymes in somatic cell tissue are very low [3]. Therefore, aerophilous stress could contribute to somatic cell necrobiosis because of anemia and reperfusion. The mechanisms underlying the hypoxia harm include; energy failure and loss of particle

\section{Springer Open}

(c) The Author(s). 2021 Open Access This article is licensed under a Creative Commons Attribution 4.0 International License, which permits use, sharing, adaptation, distribution and reproduction in any medium or format, as long as you give appropriate credit to the original author(s) and the source, provide a link to the Creative Commons licence, and indicate if changes were made. The images or other third party material in this article are included in the article's Creative Commons licence, unless indicated otherwise in a credit line to the material. If material is not included in the article's Creative Commons licence and your intended use is not permitted by statutory regulation or exceeds the permitted use, you will need to obtain permission directly from the copyright holder. To view a copy of this licence, visit http://creativecommons.org/licenses/by/4.0/. 
physiological state, excitotoxicity, loss of calcium physiological state, acidosis, cytokines and inflammation, changes in systems control protein synthesis, native microvascular reaction to ischemia-reperfusion (I/R), production of free radicals, alterations in genes expression and necrobiosis either apoptotic or death necrobiosis.

Global cerebral ischemia (GCA), is stated by the essential reduction of cerebral blood flow within the whole brain, induces by selective somatic cell injury within the cornu ammonis 1 (CA1) region of the hippocampus as long as ischemia persists. Focal brain ischemia reduces blood flow towards a selected brain region, increasing the chance of necrobiosis thereto a specific space. Among minutes of blood vessels occlusion, brain tissue develops a shortage of aldohexose and oxygen, and therefore the acidic byproducts of metabolism accumulate. This loss of substrate and reduction in $\mathrm{pH}$ level ends up in stopping the electron transport chain activity among mitochondria, which ends up in a very speedy decline in Adenosine triphosphate (ATP) concentration. Loss of ATP ends up in failure of the Na, K-ATPase, which ends up in a very marked intracellular increase in $\mathrm{Na}^{++}$concentration [4].

R.communis L. is grown in tropical and subtropical zone worldwide belongs to the family Euphorbiaceae (Ogunniyi 2006). The primary phytochemical study of R.communis shows the presence of flavonoids, saponins, steroids, alkaloids, and glycosides. The principal use of castor oil is as a laxative and purgative. Pharmacological study reveals antioxidant, antinociceptive, antiinflammatory, wound healing, antiasthmatic, antifertility, hepatoprotective, antidiabetic, and antiulcer activity [1].

The literature review suggests that Ricinus communis possess different pharmacological activities. However, no there was no literature found which suggests that Ricinus communis leaves has been utilized for the assessment of neuroprotective activity on reperfusion and cerebral ischemic injury in rats. Hence, the present work was designed to examine the cerebroprotective effect of Ricinus communis leaves extracts against the Ischemiareperfusion injury model.

\section{Materials and methods \\ Chemicals}

The chemicals used were of analytical grade and were procured from sigma chemical Co, and Qualigens fine chemicals, Mumbai, India. Ricinus communis leaves were collected from Basha, Kursi Road, Lucknow.

\section{Animals}

Male SD rat (200-250 g) was procured from the animal house of Central drug research institute (CDRI),
Lucknow, India. The animals were acclimatized by keeping them under standard laboratory conditions, the $12 \mathrm{~h}$ light/dark cycle was maintained with sufficient oxygen supply, and food \& water was provided ad-libitum.

\section{Ethical approval}

The entire experiment was conducted according to the guidelines of the committee for control and supervision of experiments on animals (CPCSEA). The experimental protocol was approved by Institutional Animal Ethical Committee (IAEC), (Reg no. 1213/PO/Re/S/08/CPCSEA, 5th June 2008), Faculty of Pharmacy, Integral University, Lucknow (U.P.) India.

\section{Preparation of extract}

The fresh leaves of the Ricinus communis plant were collected, cleared from dirt then, dried beneath shade for approximately 15 days. Some leaves were placed inside the sample bags and submitted for authentication with a voucher number (IU/2018/17-02) to Dr. Mohammad Arif, Botanist, Integral University, Lucknow, after approval, all collected leaves were coarsely pulverized using a mechanical grinder. The ground material was subjected to soxhlet extraction $\left(45-55^{\circ} \mathrm{C}\right)$ using hydroalcoholic ethanol as solvent. The extract was finally air-dried completely to get rid of all traces of the solvent and the proportion yield was found to be $21.30 \% \mathrm{w} / \mathrm{w}$. The extract was stored during airtight box placed inside refrigerator below $4{ }^{\circ} \mathrm{C}$ and further used for pharmacologic investigation.

\section{Experimental protocol \\ Drug treatment}

SD rats were divided into five groups of five rats each and fed with extract or vehicle $(0.1 \%$ carboxy methyl cellulose $\mathrm{CMC}$ ) for $7 \mathrm{~d}$ before the experiment. The doses were selected as per the acute and sub-acute studies carried out. The acute toxicity revealed the extract is safe up to $8000 \mathrm{mg} / \mathrm{Kg}$ while subacute toxicity report suggest $1000 \mathrm{mg} / \mathrm{kg}$ would be safe. So, after analyzing the report of acute and sub-acute toxicity study we have selected 250 and $500 \mathrm{mg} / \mathrm{Kg}$ as therapeutic dose to continue the work $[2,3]$.

Group I: (Sham control) (Sham) $(n=5)$ : Animals were pretreated for 14 days with $0.1 \%$ CMC $(1 \mathrm{ml} / \mathrm{kg})$ (p.o.), this group is not subjected to global cerebral ischemia on the 15th day.

Group II: (Ischemic Reperfusion) (I/R) $(n=5)$ : Animals were pretreated for 14 days with $0.1 \%$ CMC $(1 \mathrm{ml} /$ $\mathrm{kg}$ ) (p.o.) before subjecting them to global cerebral ischemia on the 15th day.

Group III: (Ricinus communis low dose) (RCLD) $(n=$ 5): Animals were pretreated for 14 days with $R$. communis extract leaves $250 \mathrm{mg} / \mathrm{kg}$ dissolved in $0.1 \%$ CMC (1 
$\mathrm{ml} / \mathrm{kg}$ ) (p.o.) before subjecting them to global cerebral ischemia on the 15th day.

Group IV: (Ricinus communis high dose) (RCHD) $(n=5)$ : Animals were pretreated for 14 days with $R$. communis extract leaves $500 \mathrm{mg} / \mathrm{kg}$ dissolved in $0.1 \%$ CMC $(1 \mathrm{ml} / \mathrm{kg}$ ) (p.o.) before subjecting them to global cerebral ischemia on the 15th day.

Group V: Standard drug-treated group (SDTG) $(n=$ 5): Animals were pretreated for 14 days with standard drug, Quercetin $25 \mathrm{mg} / \mathrm{kg}$ dissolved in 0.1\% CMC (1 ml/ $\mathrm{kg}$ ) (p.o.) before subjecting them to global cerebral ischemia on the 15th day.

\section{Induction of global brain ischemia}

Each rat was anesthetized with thiopentone sodium. Within a few min, the rat became unconscious, then rats were placed in the supine position and exposed to the light source to keep it warm. After that, a midline ventral small skin incision in the neck was made and the paratracheal muscles and fascia were splitted and pulled by stay sutures to expose the trachea, carotid arteries, and vagal nerves. Both common carotid arteries were exposed, and special attention was paid to separate and preserve the vagus nerve fibers and global cerebral ischemia was induced by BCCAO by using vascular clamps for $30 \mathrm{~min}$. After $30 \mathrm{~min}$ is over, it was assumed that global cerebral ischemia is induced, the clamps were then removed thus allowing the reflow of blood for $24 \mathrm{~h}$ through carotid arteries (reperfusion) [4].

\section{Behavioral parameters}

Neurodeficit score through lateral push test

This test was performed according to Bederson et al. [5].

\section{Measurement of locomotor activity (ambulation) by actophotometer}

Measurement of locomotor activity (ambulation) was recorded by using instrument actophotometer by using the method of Fox [6].

\section{Grip strength measurement}

This parameter was performed by the method of Bohannon [7].

\section{Elevated plus maze test for spatial memory}

Elevated plus maze test for spatial memory was performed by using the method of Harrison et al. [8].

\section{Biochemical estimations}

\section{Preparation of PMS (post mitochondrial supernatant)}

Preparation of PMS by using brain tissue was performed by using the method of Sturtz et al. [9].

\section{Acetyl cholinesterase activity in brain}

Acetyl cholinesterase activity was performed as per the details mentioned in Table 1 and was calculated according to Pavlov et al. [10] using the following formula:

$$
\mathrm{R}=\frac{\delta \mathrm{O} . \mathrm{D} . \times \text { volume of assay }(3 \mathrm{ml})}{(13,600) \times \mathrm{mg} \text { of protein }}
$$

Where $R$ = rate of enzyme activity in 'n' mole of acetylthiocholine iodide hydrolyzed/minute /mg of protein.

$\delta$ O.D. = change in absorbance $/$ minute.

$\mathrm{E}=$ extinction coefficient $=13,600 / \mathrm{M} / \mathrm{cm}$.

\section{Estimation of Thio barbituric acid reactive substances (TBARS)}

The amount of Malondialdehyde (MDA) present in a sample was estimated by the method of Nowak et al. [11] and calculated according to the equation:

$$
\mathrm{nM} \text { of } \mathrm{MDA}=\frac{\mathrm{OD} \text { at } 540 \mathrm{~nm} \mathrm{XV}}{0.156}
$$

Where $\mathrm{V}$ is the final volume of the test solution.

\section{Catalase}

Catalase activity was estimated by the method of Schriner et al. [12] and calculated as $n$ moles of $\mathrm{H}_{2} \mathrm{O}_{2}$ consumed $/ \mathrm{minute} / \mathrm{mg}$ protein

$$
\text { Catalase }=\frac{\Delta \mathrm{A} / \text { minute } \times \text { volume of assay }}{0.081 \times \text { volume of homogenate } \times \text { mg of protein }}
$$

\section{Superoxide dismutase}

A simple and rapid method for assay of SOD is described by Chowdhuri et al. [13]. One unit of SOD is described as the amount of enzyme required to cause $50 \%$ inhibition of pyrogallol auto-oxidation per $3 \mathrm{ml}$ of assay mixture and given by the formula:

$$
\text { Unit of SOD per ml of sample }=\frac{(\mathrm{A}-\mathrm{B}) \mathrm{X} 100}{\mathrm{~A} \text { X } 50}
$$

Where $\mathrm{A}$ is the difference of absorbance in $1 \mathrm{~min}$ in control.

$\mathrm{B}$ is the difference of absorbance in $1 \mathrm{~min}$ in the test sample.

Data were expressed as SOD units per mg of protein.

\section{Protein estimation using folin reagent}

Protein reacts with Folin Ciocalteau reagent was performed according to Nakka et al. [14].

\section{Preparation of the calibration curve for protein}

The calibration standard curve was plotted and used to calculate the concentration of protein in each $\mathrm{ml}$ 
Table 1 Estimation of Brain Acetylcholinesterase (AChE) Activity

\begin{tabular}{llll}
\hline Test tubes & Blank $(\mathbf{m l})$ & Test $(\mathbf{m l})$ & Pre-incubated at $37^{\circ} \mathrm{C}$ for 5 mins. \\
Phosphate buffer & 2.8 & 0.7 & 0.1 \\
DTNB & 0.1 & 0.1 \\
PMS (1\%) & 0.0 & 0.1 \\
Acetylthiocholine iodide & 0.1 &
\end{tabular}

Where DTNB (5,5'-dithiobis-(2-nitrobenzoic acid)), PMS Phenazine methosulfate

suspension of the sample [14]. The calibration curve for protein has been mentioned in Fig. 1.

\section{Tissue swelling}

Tissue swelling percentage was calculated according to Swanson [15] using the following formula

$$
\% \text { Tissue Swelling }=\frac{[(\text { VRight hemisphere-VLeft Hemisphere })]}{\text { VLeft Hemisphere }} \text { X } 100
$$

\section{Transverse section of brain}

After $24 \mathrm{~h}$ of BCCAO reperfusion, the mouse survived had been weighed, deeply anesthetized with diethyl ether, and sacrificed following the approved protocol. The brain was cautiously removed and positioned in a mouse brain matrix cutter, and the complete cerebrum is coronally sectioned at $2 \mathrm{~mm}$ durations. The sections are dipped in $2 \%$ TTC in phosphate-buffered saline (PBS) at $37^{\circ} \mathrm{C}$ for $20 \mathrm{~min}$. The slide of the sections was prepared and pictomicrograph was obtained with the help of the virtual digital camera.

\section{Histopathological examination}

Animals were sacrificed by decapitation The brains have been removed and were fixed for $48 \mathrm{~h}$ in $4 \%$ PBSbuffered formaldehyde. The tissue was reduced to $3 \mathrm{~mm}$ thickness and each block were embedded in paraffin. After fixing and processing tissue sections, different coronal serial slices $(5 \mu \mathrm{m}$ thick) were prepared for traditional histological examination. These sections were stained with hematoxylin and eosin and under a microscope histopathological examination was performed and pictures were obtained by digital camera.

\section{Statistical analysis}

All the values are expressed as mean \pm S.E.M. Data were analyzed using one-way analysis of variance (ANOVA) followed by Dennett's multiple comparison test. Where ischemic-reperfusion group (I/R) was compared with the Sham group, while all treatment groups (RCLD, RCHD, SDTG) were compared with $\mathrm{I} / \mathrm{R}$ groups. (For all the tests, $p<0.05$ was set as criteria for statistical significance.

\section{Results}

Effects of Ricinus communis leaves extract on neurodeficit score of ischemia-reperfusion injured rats

Sham group animals didn't shown any alteration in motor coordination and neurological scores. The ischemic reperfusion rats showed significantly elevated neurodeficit scores from 0 to $3.2302 \pm 0.039$ and impairment in motor coordination has been reported. Ricinus communis leaves extract showed as $1.1477 \pm 0.007$ and $0.3737 \pm 0.00$ in 250 and $500 \mathrm{mg} / \mathrm{kg}$ doses of extract respectively, compared to ischemia-reperfusion (I/R) group $3.2302 \pm 0.039$. On the contrary, the result indicates that Ricinus communis leaves extract significantly improved motor impairment and neurological score against ischemia-reperfusion injury (Fig. 2).

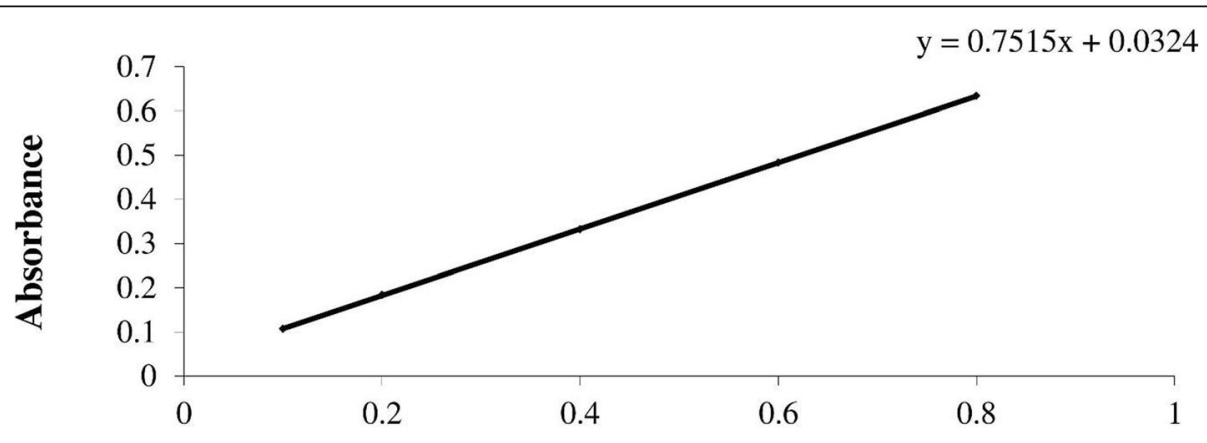

Protein conc. $(\mathbf{m g} / \mathrm{ml})$

Fig. 1 Calibration curve for protein 


\section{Behavioural Parameter}

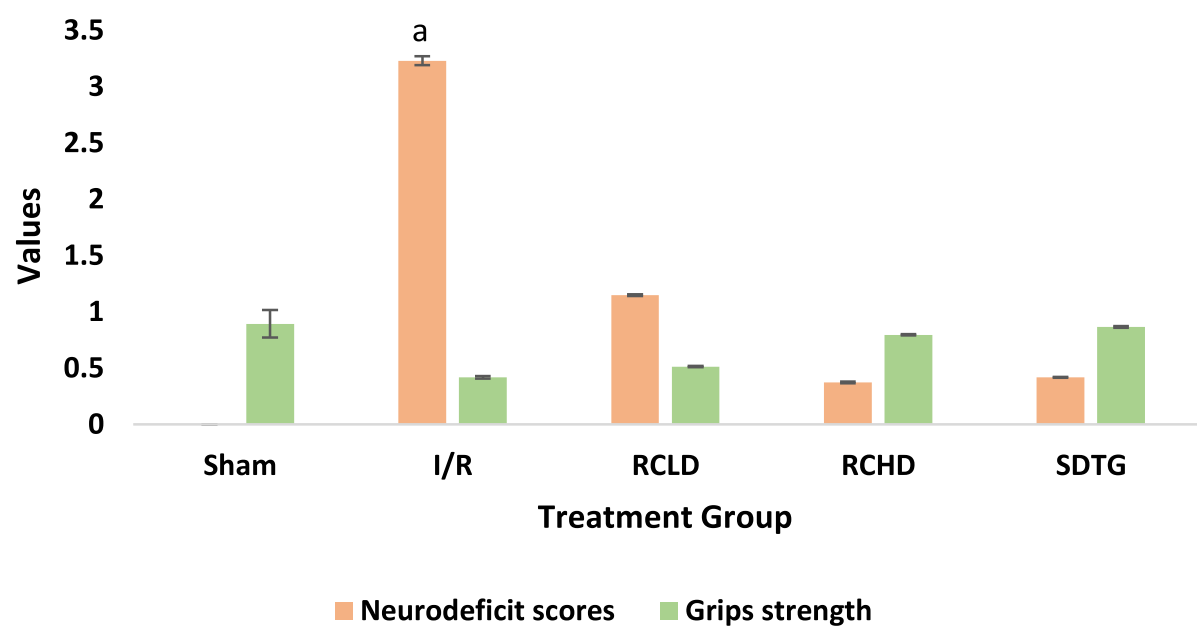

Fig. 2 Behavioral parameter estimation (neuro deficit score and grip strength) in different treatment groups. Where, values are indicated as mean \pm SEM; $(n=5)$ in each group. Data were subjected to one-way ANOVA followed by Dunnett's test when RCLD, RCHD, and SDTG groups were compared to the I/R group, while the I/R group was compared to the Sham group. ${ }^{a} p<0.01$, when compared to Sham Group, ${ }^{C} p<0.01$ when compared to I/R group. The neuro deficit score was expressed in number while grip strength is expressed as kilogram (kg)

Effects of Ricinus communis leaves extract on digital grip strength meter of ischemia-reperfusion injured rats The ischemic reperfusion rats produced a significant reduction in grip strength $0.4181 \pm 0.011 \mathrm{lbf}$ when compared to Sham group $0.85 \pm 0.122 \mathrm{lbf}$. Ricinus communis leaves extract $(250 \mathrm{mg} / \mathrm{kg})$ pretreatment showed a significant increase of $0.5146 \pm 0.007$ in the grip strength when compared to the ischemia-reperfusion (I/R) group. However, Ricinus communis leaves extract $(500 \mathrm{mg} / \mathrm{kg}$ ) showed significant effects of $0.9664 \pm 0.005$ on grip strength when compared to the ischemia-reperfusion (I/ R) group of $0.85 \pm 0.122$ (Fig. 2).

\section{Locomotor activity}

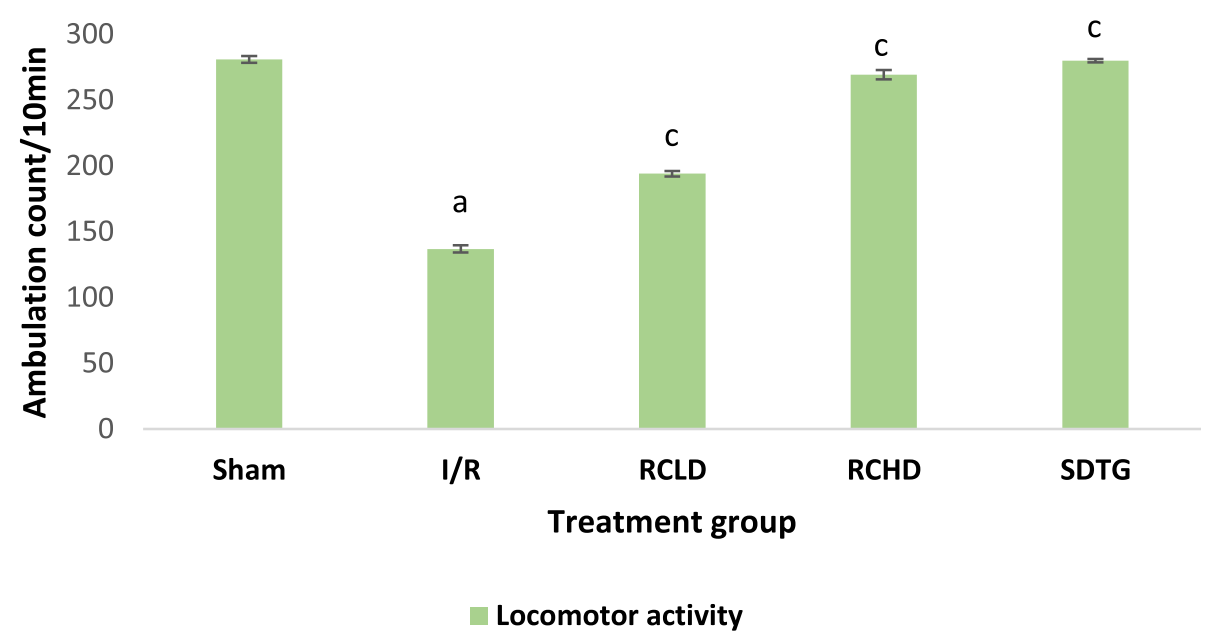

Fig. 3 Behavioral parameter estimation (locomotor activity) in the different treatment groups. Where, values are indicated as mean \pm SEM; $(n=5)$ in each group. Data were subjected to one-way ANOVA followed by Dunnett's test when RCLD, RCHD, and SDTG groups were compared to the I/R group, while the I/R group was compared to the Sham group. ${ }^{a} p<0.01$, when compared to Sham Group, ${ }^{c} p<0.01$ when compared to I/R group 
Effects of Ricinus communis leaves extract on locomotor activity of ischemia-reperfusion injured rats

The animals of ischemic reperfusion (I/R) groups with $30 \mathrm{~min}$ of BCCAO followed by $24 \mathrm{~h}$ of reperfusion significantly altered locomotors activity when compared to Sham rats $281 \pm 2.47$. Pretreatment with Ricinus communis leaves extract showed increased $194.2 \pm 1.068$ and $269.4 \pm 1.631$ respectively with 250 and $500 \mathrm{mg} / \mathrm{kg}$ locomotors activity when compared to ischemia-reperfusion (I/R) group rats $137 \pm 2.77$ (Fig. 3 ).

\section{Elevated plus maze test for spatial memory}

Elevated plus maze test for spatial memory shows that Initial latency (IL) does not show any significant difference in any of the treated groups. A significant decrease in second retention latency (SRL) and first retention latency (FRL) is observed in the Sham group after $24 \mathrm{~h}$ of surgery which shows retention of memory. The animals challenged with $30 \mathrm{~min}$ of BCCAO followed by $24 \mathrm{~h}$ of reperfusion in ischemic reperfusion (I/R) groups produced a significant elevation in the transfer latency time in an elevated plus maze when compared to sham control group rats. Pretreatment with Ricinus communis leaves extract $250 \mathrm{mg} / \mathrm{kg}$ significantly attenuated the increase in the FRL and SRL when compared to the ischemia reperfusion (I/R) group. However, Ricinus communis leaves extract $500 \mathrm{mg} / \mathrm{kg}$ significantly increases the FRL and SRL paradigm in the elevated plus maze more than standard drug-treated groups of rats $64.8 \pm 0.5831$ (Fig. 4).

\section{Acetylcholinesterase (Ache) activity}

Effect of Ricinus communis leaves extract on acetylcholinesterase (Ache) activity has been studied in ischemia-reperfusion injury in rats and the result has been shown in (Fig. 5).

\section{Effects of Ricinus communis leaves extract on oxidative stress parameters of ischemia reperfused injured rats} When animals were undergone BCCAO followed by 24 $h$ reperfusion caused oxidative damage marked by attenuation of lipid peroxidation, reduced catalase and superoxide dismutase activity in the brain when compared to Sham rats. Pretreatment with Ricinus communis leaves $(250$ and $500 \mathrm{mg} / \mathrm{kg})$ significantly helped in regaining depleted catalase activity as well as reducing elevated lipid peroxidation of the brain, when compared to their respective control (I/R group) (Fig. 6).

\section{Tissue swelling}

The tissue swelling was expressed as a percentage and swelling of the brain hemisphere in the Sham group was found to be zero. Ischemic-reperfusion (I/R) groups showed a maximum percentage of tissue swelling (7.8\%), the $R$. communis group at a low dose (RCLD) showed about (5.5\%), while its high dose showed about $3.9 \%$ swelling. The Standard drug-treated group (SDTG) showed the least swelling i.e. 2.1\% (Fig. 5).

\section{Transverse section of brain}

After TTC staining, the area of tissue in which infraction has occurred is shown as a white (unstained) tissue next

\section{Spatial memory test}

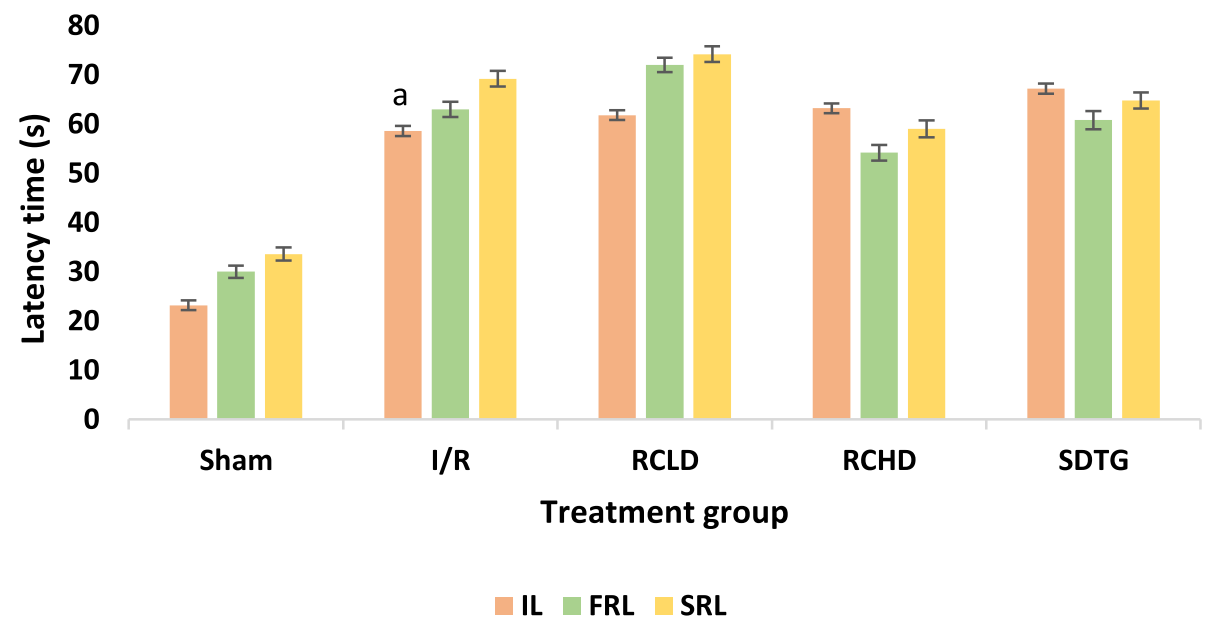

Fig. 4 Spatial memory test via elevated maize model in the different treatment groups. Where, values are indicated as mean $\pm \mathrm{SEM} ;(n=5)$ in each group. Data were subjected to one-way ANOVA followed by Dunnett's test when RCLD, RCHD, and SDTG groups were compared to the I/R group, while the I/R group was compared to the Sham group. ${ }^{a} p<0.01$, when compared to Sham Group, ${ }^{b} p<0.05,{ }^{C} p<0.01,{ }^{d} p<0.001$ when compared to I/R group 


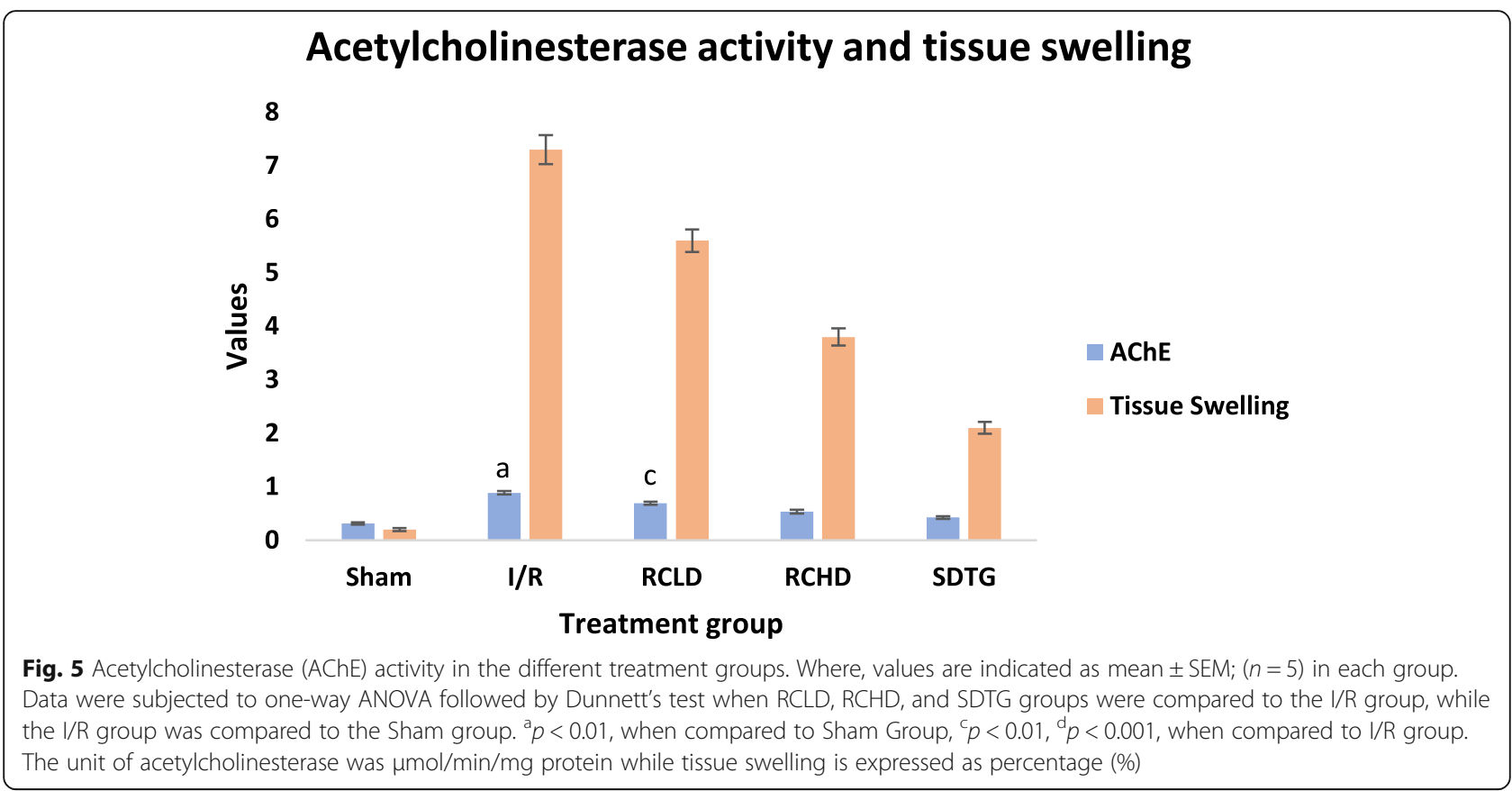

to the red brick colored (viable) tissue, thus showing a significant increase in red tissue in the treated group when compared with the ischaemic group (Fig. 7).

\section{Histopathology}

Photomicrograph shows that regular brain (cortex) morphology was observed, no histopathological abnormalities were observed in the sham group and staining was uniform (Fig. 8a). In the Ischemia-reperfusion (I/R) group Cerebral area was disordered, irregular morphology was observed, shrinkage was observed showed the meningeal changes vacuolization and edema and cell gaps were widened (Fig. 8b). The pycnotic neurons in the brain cortex were found, the cerebral area was better, irregular morphology was reduced, eosinophilic neurons at the ischemic area has been decreased, vacuolization and edema are reduced in low dose (RCLD) (Fig. 8c). Whereas the High dose group (RCHD)

\section{Oxidative stress parameter}

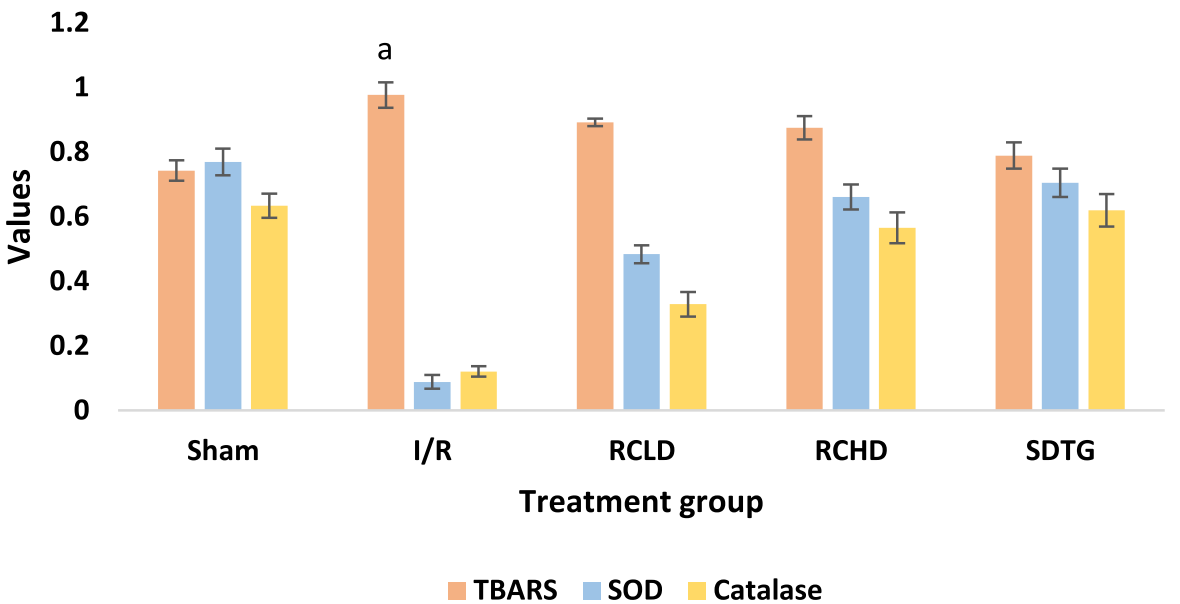

Fig. 6 Oxidative stress parameter in the different treatment groups. Where, values are indicated as mean \pm SEM; $(n=5)$ in each group. Data were subjected to one-way ANOVA followed by Dunnett's test when RCLD, RCHD, and SDTG groups were compared to the I/R group, while the I/R group was compared to the Sham group. ${ }^{a} p<0.01$, when compared to Sham group, ${ }^{b} p<0.05,{ }^{c} p<0.01,{ }^{d} p<0.001$ when compared to I/R group. The catalase was expressed $n$ moles of $\mathrm{H}_{2} \mathrm{O}_{2}$ consumed/minute/mg protein, SOD was expressed as SOD units per mg of protein. The unit of TBARS is TBARS (nmoles/wet tissue) 


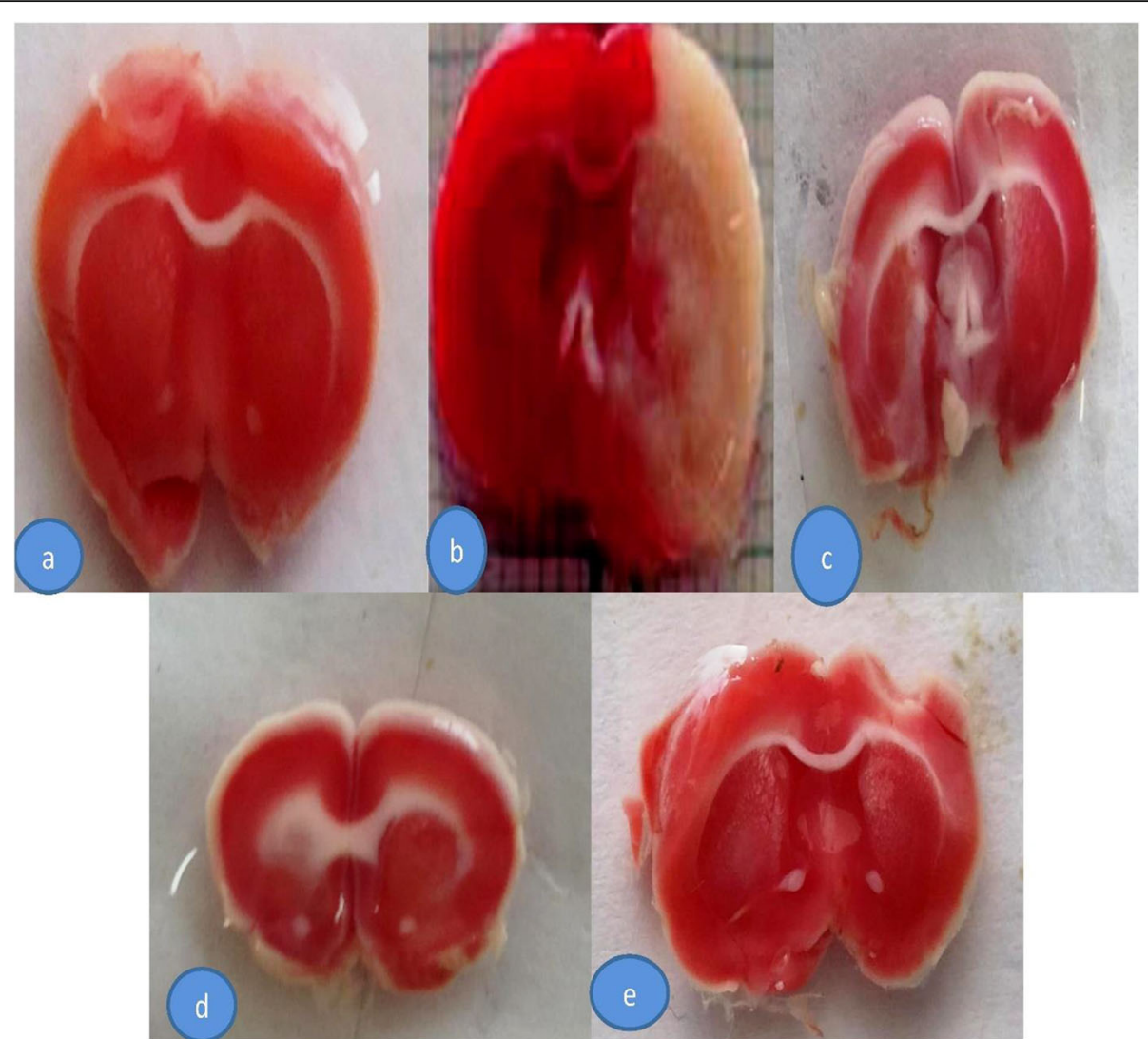

Fig. 7 Transverse sections of brain from different treatment groups stained with TTC. (a.) Sham control (Sham) (b.) Ischemic Reperfusion group (I/ R) (c.) (Ricinus communis Low dose) (RCLD) (d.) Ricinus communis High dose (RCHD) (e.) (Standard drug-treated group) (SDTG)

pictomicrograph showed regular cerebral morphology and staining was uniform, most of the cells were still located in the muscle membrane, degeneration was not obvious and the cell gap was slightly wide (Fig. 8d). The Ischemia-reperfusion injury was least in the standard drug-treated group (SDTG) (Fig. 8e).

\section{Discussion}

Ischemia-reperfusion associated with thrombolytic therapy, organ transplantation, coronary angioplasty, aortic cross-clamping, or cardiopulmonary bypass results in local and systemic inflammation. Brain stroke is a sudden loss of brain function usually caused by blockage or leakage of a blood vessel. It develops from a complex cascade of cellular events that ultimately leads to cerebral infarction and causes a sudden loss of vision \& balance, coordination, speech, and memory. The present study was undertaken to evaluate the neuroprotective effect of Ricinus communis leaves extract on ischemiareperfusion brain injury in rats. The neurotoxicity was produced by blocking the internal carotid artery with the help of a microvascular clip followed by reperfusion. Reperfusion of ischemic tissue results in the formation of toxic reactive oxygen species (ROS) including, $\mathrm{O}_{2-}$, $\mathrm{OH}^{-}, \mathrm{HOCl}, \mathrm{H}_{2} \mathrm{O}_{2}$, and nitric oxide-derived peroxynitrite radicals. This toxic ROS induces oxidative stress [16]. Oxidative stress and the antioxidant system play very important role in pathophysiology behind brain disorders. Moderate stress trigger apoptosis, Severe oxidative stress cause cell death, further more intense stresses may cause necrosis. Generation of ROS can be eliminated or decreased via numerous nonenzymatic and enzymatic reactions. The final end product of ROS via lipid peroxidation is malondialdehyde, that could form thiobarbituric acid reactive species (TBARS), would be confirmed spectrophotometrically [17].

SOD, which catalyzes the dismutation of the superoxide anion $\left(\mathrm{O}_{2}^{-}\right)$into molecular oxygen and hydrogen peroxide, is one of the utmost significant antioxidative enzymes [18]. Catalase is enzymatic antioxidant, widely distributed in all animal tissues that decompose hydrogen peroxide and protect the tissue from highly reactive hydroxyl radicals. In the present study, TBARS level was increased while CAT and SOD activity was reduced in the ischemic reperfused group in compared to the Sham group. Therefore, reduced activity of these enzymes may 


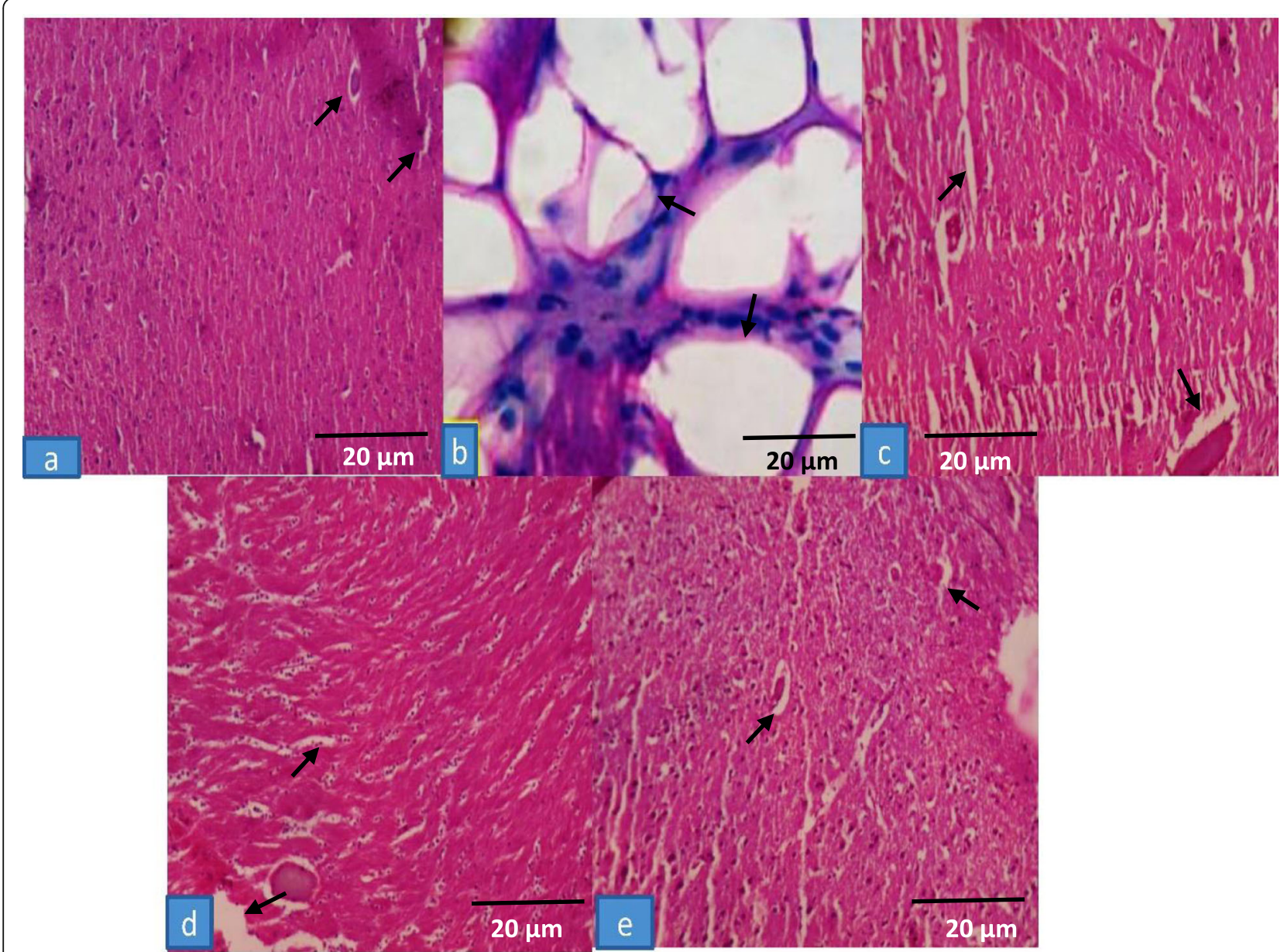

Fig. 8 Histopathology of brain sections from different treatment groups stained with hematoxylin and eosin. (a.) Sham control (Sham) (b.) Ischemic Reperfusion group (I/R) (c.) (Ricinus communis Low dose) (RCLD) (d.) Ricinus communis High dose (RCHD) (e.) (Standard drug-treated group) (SDTG)

result in many toxic effects due to generation of superoxide and hydrogen peroxide, associated biomarkers for neurodegenerative disorder [19].

Data revealed progressive improvement in antioxidant effect with increased doses of Ricinus communis leaves extracts by enhancing activity of catalase and SOD, while significant reduction in TBARS level. Such findings are in congruence with previous studies demonstrating the beneficial effects of Ricinus communis leaves extract in decreasing oxidative stress and encouraging functional recovery specially in ischemic rat model.

Oxidative free radicals are identified and trigger in development of ischemic brain damage. Histopathological observations of the present study exposed that acute ischemia-reperfusion leads to extensive ischemic neuronal changes or neuronal cell death. This might be correlated with earlier experimental reports [20]. The presence of neuronal death/loss can be due to the deactivation of Glial cells, thus leading to the permanent death of neurons [21]. Therefore, it is likely that an injury may be revealed if ischemia-reperfusion is protracted beyond this time point. On the other hand, the histological injury would have been deceptive if more sophisticated procedures of evaluation such as electron microscopy were used [22].

From these results, it was inferred that administration of Ricinus communis leaves extract in RCLD and RCHD treated rats attenuated brain oxidative damages, decreased activity of antioxidant enzymes, catalase, and TBARS. These antioxidant effects of Ricinus communis leave extract might be associated with the enhancement in performance in the passive avoidance behavioral test. Although the mechanisms underlying these effects are still unknown and require more pharmacological, neurochemical, and pharmacokinetic research to establish any therapeutic advantage. However, regular use of Ricinus communis leaves extract could be suggested for the prevention of cognitive decline during aging and neurodegenerative disease. 


\section{Conclusions}

The earlier reports support that the Ricinus communis has potent antioxidant activity, its seeds may be proved as neuroprotective against focal ischemia-reperfusion induced brain injury, so leaf was chosen for the present study. The neuroprotective effect of Ricinus communis leaves extract and quercetin as reference was tested in ischemic rats. In this study, we confirm that the hydroalcoholic leaves extracts at dose $500 \mathrm{mg} / \mathrm{kg}$ body wt of Ricinus communis significantly improved the ischemiainduced neurological status, forelimb strength, balance, and co-ordination i.e. motor performance, neurodeficit score, grip strength test, plus-maze. The results obtained in this study are supported by a recently published study where Ricinus communis seed produced positive effects in global cerebral ischemia-reperfusion brain injury due to its antioxidant potential [23].

In the present study, the biochemical investigations reveal that Ricinus communis significantly increased the catalase and superoxide dismutase enzyme activities, which indicates that Ricinus communis may decrease the formation of free radicals. Also, Ricinus communis reduced the malondialdehyde which is the marker of lipid peroxidation, suggesting that the antioxidant potential of Ricinus communis [24]. The finding in this study is supported by the previous studies where (curcumin, silymarin) [25] [26] containing antioxidant potential have counteracted the ROS generation during ischemiareperfusion induced brain injury. The phytoconstituents present in Ricinus communis are quercetin and phenolic compounds, which have been already proved to be a potent antioxidant. This all finding summarizes the neuroprotective effects of Ricinus communis leaves extract. The effect observed as protectant in preclinical ischemic animal models confirm anti-inflammatory effect and could be useful for neuroprotection in clinical findings. Significant efforts has to be done so that Ricinus extract being discovered could be useful for human administration as prevention measure against stroke. So clinical studies needed to further extend the therapeutic application of Ricinus extract.

Based on these findings, we conclude that Ricinus communis have improved the ischemia reperfusioninduced neurological deficit, motor performance on grips strength and locomotor activity test, and by exerting the antioxidant effects. Thus, it may be useful in the treatment of stroke. Further investigations with the isolation of purified active phytoconstituents of Ricinus communis may be required to validate the neuroprotective and antioxidant effects.

\section{Abbreviation}

RC: Ricinus communis; BCCAO: Bilateral common carotid artery occlusion;

SD: Sprague Dawley; p.o.: per oral; AHD: Aldohexose deprivation; I/

R: Ischaemia-reperfusion; CA1: Cornu ammonis 1; GCA: Global cerebral ischaemia; ATP: Adenosine triphosphate; CDRI: Central drug research institute; CPCSEA: Committee for the purpose of control and supervision of experiments on animals; IAEC: Institutional Animal Ethical Committee; PMS: Post mitochondrial supernatant; TBARS: Thio Barbituric Acid Reactive Substances; MDA: Malondialdehyde; SOD: Superoxide dismutase; TTC: 2,3,5Triphenyltetrazolium chloride, PBS-Phosphate buffered saline;

ANOVA: Analysis of variance; RTL: Retention transfer latency; RCLD: Ricinus communis low dose; RCHD: Ricinus communis high dose; Standard drug: treated group (SDTG); S.E.M: Standard error of the mean; ROS: Reactive oxygen species

\section{Acknowledgments}

The author sincerely pays his heartfelt respect and gratitude toward Prof. Syed Waseem Akhtar, Hon. Chancellor and Prof. Javed Mussarat, Hon. ViceChancellor, Integral University for providing an excellent research environment. The university has provided a manuscript communication number for further communication (IU/R\&D/2019-MCN000522).

\section{Authors' contributions}

NA performed the research work and interpreted the data, AM has designed the research work, the research work was monitored by FA, ZK helped in preparing the manuscript. All the authors have accepted responsibility for the entire content of this submitted manuscript and approved submission.

\section{Funding}

NIL

Availability of data and materials

The data are mentioned in this manuscript, No data is available as supplementary data.

\section{Declarations}

Ethics approval and consent to participate

The study protocols were also reviewed and approved by Institutional Animal Ethical Committee (IAEC), Faculty of Pharmacy, Integral University, Lucknow (Reg no. 1213/PO/Re/S/08/CPCSEA, 5th June 2008) having approval no. IU/IAEC/17/04.

\section{Consent for publication}

No data, figures, tables were taken from any author in this manuscript.

\section{Competing interests}

The authors declare no potential conflicts of interest concerning the research, authorship, and/or publication of this article.

Received: 19 June 2020 Accepted: 1 November 2021

Published online: 12 November 2021

References

1. Marwat SK, Rehman F, Khan EA, Baloch MS, Sadiq M, Ullah I, et al. Review Ricinus cmmunis - Ethnomedicinal uses and pharmacological activities. Pak J Pharm Sci. 2017;30(5):1815-27.

2. Gebeslassie H, Ekanem PE, Gebrelibanos M, Assefa H, Belsty T, Kebele H. Biochemical and pathological assessment of ricinus communis leaf extract administration on liver and kidney in mice. Int J Med Biomed Stud. 2019; 3(4):126-33. https://doi.org/10.32553/ijmbs.v3i4.192.

3. Sadashiv PS. Acute toxicity study for Ricinus communis. Der Pharm Lett 2011;3:132-7 www.scholarsresearchlibrary.com.

4. Chandrashekhar VM, Ranpariya VL, Ganapaty S, Parashar A, Muchandi AA. Neuroprotective activity of Matricaria recutita Linn against global model of ischemia in rats. J Ethnopharmacol. 2010;127(3):645-51. https://doi.org/10.1 016/j.jep.2009.12.009.

5. Bederson JB, Pitts LH, Tsuji M, Nishimura MC, Davis RL, Bartkowski H. Rat middle cerebral artery occlusion: evaluation of the model and development of a neurologic examination. Stroke. 1986;17(3):472-6. https://doi.org/10.11 61/01.STR.17.3.472

6. Fox MD, Raichle ME. Spontaneous fluctuations in brain activity observed with functional magnetic resonance imaging. Nat Rev Neurosci. 2007;8(9): 700-11. https://doi.org/10.1038/nrn2201. 
7. Bohannon RW. Reference values for extremity muscle strength obtained by hand-held dynamometry from adults aged 20 to 79 years. Arch Phys Med Rehabil. 1997;78(1):26-32. https://doi.org/10.1016/S0003-9993(97)90005-8.

8. Harrison FE, Hosseini AH, Mcdonald MP. Endogenous anxiety and stress responses in water maze and Barnes maze spatial memory tasks. Behav Brain Res. 2009;198(1):247-51. https://doi.org/10.1016/j.bbr.2008.10.015.

9. Sturtz LA, Diekert K, Jensen LT, Lill R, Culotta VC. A fraction of yeast Cu,Znsuperoxide dismutase and its metallochaperone, CCS, localize to the intermembrane space of mitochondria. A physiological role for SOD1 in guarding against mitochondrial oxidative damage. J Biol Chem. 2001; 276(41):38084-9. https://doi.org/10.1074/jbc.M105296200.

10. Ellman GL, Courtney KD, Andres V, Featherstone RM. A new and rapid colorimetric determination of acetylcholinesterase activity. Biochem Pharmacol. 1961;7(2):88-95. https://doi.org/10.1016/0006-2952(61)90145-9.

11. Nowak D, Kalucka S, Białasiewicz P, Król M. Exhalation of $\mathrm{H} 2 \mathrm{O} 2$ and thiobarbituric acid reactive substances (TBARs) by healthy subjects. Free Radic Biol Med. 2001;30(2):178-86. https://doi.org/10.1016/S0891-584 9(00)00457-3.

12. Schriner SE, Linford NJ, Martin GM, Treuting P, Ogburn CE, Emond M, et al Extension of Murine Life Span by Overexpression of Catalase Targeted to Mitochondria. Science. 2005;308:1909-11.

13. Chowdhuri DK, Parmar D, Kakkar P, Shukla R, Seth PK, Srimal RC. Antistress effects of bacosides of Bacopa monnieri: modulation of Hsp70 expression, superoxide dismutase and cytochrome P450 activity in rat brain. Phyther Res. 2002;16(7):639-45. https://doi.org/10.1002/ptr.1023.

14. Nakka VP, Gusain A, Raghubir R. Endoplasmic reticulum stress plays critical role in brain damage after cerebral ischemia/reperfusion in rats. Neurotox Res Springer-Verlag. 2010;17(2):189-202. https://doi.org/10.1007/s12640-0099110-5.

15. Swanson RA. A Semiautomated method for measuring brain infarct volume J Cereb Blood Flow Metab. 1990;10(2):290-4. https://doi.org/10.1038/jcbfm.1 990.47.

16. Khan RA, Khan MR, Sahreen S, Bokhari J. Prevention of CCl4-induced nephrotoxicity with Sonchus asper in rat. Food Chem Toxicol. 2010;48(8-9): 2469-76. https://doi.org/10.1016/j.fct.2010.06.016.

17. Dib M, Garrel C, Favier A, Robin V, Desnuelle C. Can malondialdehyde be used as a biological marker of progression in neurodegenerative disease? J Neurol. 2002;249:367-74.

18. Butchi Akondi R, Kumar P, Annapurna A, Pujari M. Protective Effect of Rutin and Naringin on Sperm Quality in Streptozotocin (STZ) Induced Type 1 Diabetic Rats. Iran J Pharm Res. 2011;10:585-96.

19. Cui X, Dai X-G, Li W-B, Zhang B-L, Fang Y-Z. Effects of Lu-duo-Wei capsules on superoxide dismutase activity and contents of malondialdehyde and lipofuscin in the brain of the housefly. Am J Chin Med. 2000;28(02):259-62. https://doi.org/10.1142/S0192415X00000301.

20. Mukherjee PK, Ahamed KFHN, Kumar V, Mukherjee K, Houghton PJ. Protective effect of biflavones from Araucaria bidwillii hook in rat cerebral ischemia/reperfusion induced oxidative stress. Behav Brain Res. 2007;178(2): 221-8. https://doi.org/10.1016/j.bbr.2006.12.025.

21. Bromont C, Marie C, Bralet J. Increased lipid peroxidation in vulnerable brain regions after transient forebrain ischemia in rats. Stroke. 1989;20(7):918-24. https://doi.org/10.1161/01.STR.20.7.918.

22. Surapaneni S, Prakash T, Ansari A, Goli D. Neuroprotective effect of Clerodendron glandulosum against acute transient ischemia reperfusion cerebral injury in rats. J Neurol Neurorehabil Res. 2017;2(01):14-20. https:// doi.org/10.35841/neurology-neurorehabilitation.2.1.14-20.

23. Lee E, Eom JE, Kim HL, Kang DH, Jun KY, Jung DS, et al. Neuroprotective effect of undecylenic acid extracted from Ricinus communis $L$. through inhibition of $\mu$-calpain. Eur J Pharm Sci. 2012;46(1-2):17-25. https://doi.org/1 0.1016/j.ejps.2012.01.015.

24. Ravishankar K, Indira N. Antioxidant Activity of Ethanolic Extract of Ricinus communis Leaf. Biomed Pharmacol J. 2015;5:179-83.

25. Menon VP, Sudheer AR. Antioxidant and anti-inflammatory properties of curcumin [Internet]. Adv Exp Med Biol. 2007;595:105-25. https://doi.org/10.1 007/978-0-387-46401-5_3.

26. Asghar Z, Masood Z. Evaluation of antioxidant properties of silymarin and its potential to inhibit peroxyl radicals in vitro. Pak J Pharm Sci. 2008;21(3): 249-54.

\section{Publisher's Note}

Springer Nature remains neutral with regard to jurisdictional claims in published maps and institutional affiliations.

\section{Submit your manuscript to a SpringerOpen ${ }^{\circ}$ journal and benefit from:}

- Convenient online submission

- Rigorous peer review

- Open access: articles freely available online

High visibility within the field

- Retaining the copyright to your article

Submit your next manuscript at $\boldsymbol{\nabla}$ springeropen.com 